ORIGINAL

\title{
Endothelial dysfunction and low grade chronic inflammation in subclinical hypothyroidism due to autoimmune thyroiditis
}

\author{
Esat Erdem Türemen ${ }^{1)}$, Berrin Çetinarslan ${ }^{1)}$, Tayfun Şahin ${ }^{2)}$, Zeynep Cantürk ${ }^{1)}$ and İlhan Tarkun ${ }^{1)}$ \\ ${ }^{1)}$ Department of Endocrinology and Metabolism, Kocaeli University, 41110, Turkey \\ 2) Department of Cardiology, Kocaeli University, 41110, Turkey
}

\begin{abstract}
The relationship betweeen subclinical hypothyroidism ( $\mathrm{SH}$ ) and cardiovascular disease has been one of the most popular topics recently. There is still some controversy concerning its cardiovascular impact and management protocols. Our study aims to investigate the presence of the well known preceding clinical situations of atherosclerosis like endothelial dysfunction and inflammation in subclinical hypothyroidism. Thirty-seven patients with subclinical hypothyroidism (29 women, 8 men) and 23 healthy volunteers (19 women, 4 men) were recruited for the study. Endothelial dysfunction was measured by examining brachial artery responses to endothelium-dependent (flow mediated dilation, FMD) and endothelium-independent stimuli (sublingual nitroglycerin (NTG)). Serum TNF-alpha, interleukin-6, and hs-CRP were measured. The estimate of insulin resistance by HOMA score was calculated with the formula: fasting serum insulin ( $\mu$ IU/ $\mathrm{mL}) \mathrm{x}$ fasting plasma glucose $(\mu \mathrm{M} / \mathrm{L}) / 22.5$. There were no significant differences in age, body mass index, waist circumference, HOMA scores. There was a statistically significant difference in endothelium-dependent (FMD) and endothelium-independent vascular responses (NTG) between the patients with subclinical hypothyroidism and the normal healthy controls. The groups were well matched for baseline brachial artery diameter. The TSH and LDL, IL-6, TNF-alpha and hs-CRP levels in the patient group were significantly higher than those in control group. A positive correlation was found only between endothelium-dependent vasodilation and TNF-alpha, hs-CRP and IL-6, TSH, total cholesterol, LDL and triglycerides. Endothelium-independent vascular response was not correlated with any of the metabolic or hormonal parameters. Neither of the groups were insulin resistant and there was not any difference either in fasting insulin or in glucose levels. We found endothelial dysfunction in subclinical hypothyroidism group. Endothelium-dependent (FMD) and endothelium-independent vascular responses (NTG) were lower in patient group. Our findings suggest that there is endothelial dysfunction and low grade chronic inflammation in SH due to autoimmune thyroiditis. There are several contributing factors which can cause endothelial dysfunction in SH such as changes in lipid profile, hyperhomocysteinemia. According to our results low grade chronic inflammation may be one of these factors.
\end{abstract}

Key words: Endothelial dysfunction, Low grade chronic inflammation, Subclinical hypothyroidism, Autoimmune thyroiditis

IT is a very well known fact that the endothelium plays a major role in vascular tone, vascular homeostasis, vascular smooth muscle cell proliferation and thrombosis and thrombolysis balance through the production of a large number of vasoactive chemicals, growth modulators and other factors that mediate these functions [1]. Endothelial dysfunction can be defined as the partial or complete loss of this balance between vaso-

Received Nov. 5, 2010; Accepted Feb. 18, 2011 as K10E-333

Released online in J-STAGE as advance publication Apr.14, 2011

Correspondence to: Esat Erdem Türemen, Anadolu Medical Center Hospital, Endocrinology and Metabolism, Cumhuriyet Mahallesi 2255 Sokak No.3 Gebze 41400 Kocaeli, Turkey.

E-mail: eturemen@gmail.com constrictors and vasodilators, growth promoting and inhibiting factors, pro-atherogenic and anti-atherogenic factors, and pro-coagulant and anti-coagulant factors [1]. It is also regarded as an early event in the atherosclerosis process [2].

The relationship between subclinical hypothyroidism (SH) and cardiovascular disease has been one of the most popular topics recently. There is still some controversy concerning its cardiovascular impact and management protocols. Our study aims to investigate the presence of the well known preceding clinical situations of atherosclerosis such as endothelial dysfunction and chronic inflammation and to assess whether systemic inlammatory markers might be related to endot- 
helial dysfunction in subclinical hypothroidism due to autoimmune thyroiditis or not.

\section{Material and Method}

Thirty-seven patients with subclinical hypothyroidism (29 women, 8 men) and twenty-three healthy volunteers (19 women, 4 men) were recruited for the study. All were given written informed consent.

Subclinical hypothyroidism is defined as "a serum TSH concentration above the statistically defined upper limit of the reference range when serum free thyroxine (FT4) and free triiodothyronine (FT3) concentrations are within their reference ranges." These thyroid function tests were documented for six months. Autoimmune thyroidititis is defined as the presence of at least one of the two antithyroid antibodies (anti-thyroid peroxidase (anti-TPO), anti-thyroglobin (anti-Tg)) and the presence of the heterogeneity in thyroidal parenchyma determined by ultrasound. All the subjects recruited for the study have subclinical hypothyroidism due to autoimmune thyroiditis. All of the other cases, due to other causes (SH due to thyroidectomy or radioiodine treatment etc.) were eliminated. The study was approved by Hospital Ethics Committee of Kocaeli University, Faculty of Medicine.

Patients who have any acute or chronic systemic disease, any malignant condition, alcoholism, tobacco use, hypertension, diabetes and who are younger than 20 years of age or older than 69 years of age were excluded from the study.

Arterial endothelium and smooth muscle functions were measured by examining brachial artery responses to endothelium-dependent (flow mediated dilatation (FMD)) stimuli and endothelium-independent stimuli (sublingual nitroglycerin (NTG)). Ultrasonographic measurements were carried out according to the method described by Coretti et al. [3]. The assessment was performed after an overnight fast in a quiet, airconditioned room $\left(22-24{ }^{\circ} \mathrm{C}\right)$ by one experienced cardiologist who was blind to diagnosis. The diameter of the brachial artery was measured on B-mode ultrasound images, using a $7.5 \mathrm{MHz}$ transducer. Ultrasound measurements were obtained using a high-resolution ultrasound machine (Toshiba Power Vision 8000). The right brachial artery was scanned in longitudinal sections $2-8 \mathrm{~cm}$ above the elbow. After detection of the right transducer position, the skin surface was marked and the arm kept in the same position during the study.
All scans were recorded on videorecorder and analyzed later. Arterial diameters were measured at rest, during reactive hyperemia, again at rest and after administration of $0.4 \mathrm{mg}$ sublingual NTG. Reactive hyperemia was induced by inflation of a pneumatic cuff on the upper arm to suprasystolic pressure, followed by cuff deflation after $4.5 \mathrm{~min}$. The diameter of the brachial artery was scanned and recorded after deflation. After a rest period of $10-15 \mathrm{~min}$, the second control scan diameter was recorded. Then sublingual NTG was administered and 3.5-4 min later, a final scan of the diameter was recorded.

The end-diastolic arterial diameter was measured from one media-adventitia interface to the other at the clearest section; measurements were taken three times at baseline, every $20 \mathrm{sec}$ after reactive hyperemia. The maximum vessel diameter was defined as the average of the three consecutive maximum diameter measurements after hyperemia. Vasodilatation by reactive hyperemia was expressed as the percentage change in diameter compared with baseline values. The intra-observer variation in our clinic was $1.5 \%$.

Serum TNF-alpha, interleukin-6, and hs-CRP were measured. The estimate of insulin resistance by HOMA-IR score was calculated using the formula: fasting serum insulin $(\mu \mathrm{IU} / \mathrm{mL}) \mathrm{x}$ fasting plasma glucose $(\mu \mathrm{M} / \mathrm{L}) / 22.5$.

\section{Results}

There were no significant differences in age, body mass index, waist circumference, HOMA scores between groups (Table 1). The groups were well matched for baseline brachial artery diameter. There were statistically significant differences in endothelium-dependent endothelial dysfunction (FMD) and endothelium-independent vascular responses (NTG) between patients with subclinical hypothyroidism and healthy control group (Table 2).

In SH group TSH, LDL, IL-6, TNF-alpha and hsCRP levels were significantly higher than controls (Table 3). IL-6, TNF-alpha and hs-CRP levels were shown in Fig. 1, Fig. 2 and Fig. 3, respectively. A positive correlation was found only between endotheliumdependent vasodilation and TNF-alpha, hs-CRP and IL-6, TSH, total cholesterol, LDL and triglycerides (Table 4). Endothelium-independent vascular response was not correlated with any of the metabolic or hormonal parameters. Neither of the groups were insulin 
Table 1 Clinical and laboratory parameters of both groups.

\begin{tabular}{lccc}
\hline & $\begin{array}{c}\text { Subclinical } \\
\text { Hypothyroidism } \\
(\mathrm{n}=37)\end{array}$ & $\begin{array}{c}\text { Controls } \\
(\mathrm{n}=23)\end{array}$ & $P$ value \\
\hline Age $($ year) & $46.35 \pm 11.41$ & $42.61 \pm 11.61$ & $\mathrm{NS}$ \\
BMI $\left(\mathrm{kg} / \mathrm{m}^{2}\right)$ & $23.68 \pm 1.73$ & $23.39 \pm 1.23$ & $\mathrm{NS}$ \\
Waist circumference $(\mathrm{cm})$ & $82.94 \pm 6.06$ & $82.86 \pm 3.92$ & $\mathrm{NS}$ \\
TSH $(\mu \mathrm{IU} / \mathrm{mL})$ & $8.31 \pm 6.4$ & $1.26 \pm 0.82$ & $<0.001^{*}$ \\
Free T4 $(\mathrm{ng} / \mathrm{dL})$ & $1.20 \pm 0.15$ & $1.29 \pm 0.14$ & $\mathrm{NS}$ \\
Anti-TPO antibody $(\mathrm{IU} / \mathrm{mL})$ & $357.93 \pm 35.44$ & $22.36 \pm 9.82$ & $<0.001^{*}$ \\
Anti-Tg antibody $(\mathrm{IU} / \mathrm{mL})$ & $229.83 \pm 17.53$ & $34.52 \pm 13.24$ & $<0.001^{*}$ \\
Thyroid volume $(\mathrm{mL})$ & $9.9 \pm 3.8$ & $8.9 \pm 4.2$ & $\mathrm{NS}$ \\
Fasting plasma glucose $(\mathrm{mg} / \mathrm{dL})$ & $92.97 \pm 4.99$ & $89.95 \pm 6.99$ & $\mathrm{NS}$ \\
Fasting insulin $(\mu \mathrm{IU} / \mathrm{mL})$ & $8.95 \pm 4.72$ & $9.01 \pm 3.87$ & $\mathrm{NS}$ \\
HOMA-IR & $2.08 \pm 1.1$ & $1.99 \pm 0.90$ & $\mathrm{NS}$ \\
Total cholesterol $(\mathrm{mg} / \mathrm{dL})$ & $203.75 \pm 41.22$ & $166.26 \pm 32.75$ & $<0.001^{*}$ \\
Triglyceride $(\mathrm{mg} / \mathrm{dL})$ & $113.45 \pm 44.68$ & $94.82 \pm 31.56$ & $\mathrm{NS}$ \\
HDL-cholesterol $(\mathrm{mg} / \mathrm{dL})$ & $52.16 \pm 13.92$ & $46.65 \pm 11.23$ & $\mathrm{NS}$ \\
LDL-cholesterol $(\mathrm{mg} / \mathrm{dL})$ & $129.11 \pm 32.40$ & $98.51 \pm 26.55$ & $<0.001^{*}$ \\
\hline
\end{tabular}

*, statistical significance; NS, No statistical significance

Table 2 Basal diameters and brachial artery responses in both groups

\begin{tabular}{lccc}
\hline & $\begin{array}{c}\text { Subclinical } \\
\text { Hypothyroidism } \\
(\mathrm{n}=37)\end{array}$ & $\begin{array}{c}\text { Controls } \\
(\mathrm{n}=23)\end{array}$ & $P$ value \\
\hline Basal diameter $(\mathrm{mm})$ & $3.64 \pm 0.37$ & $3.71 \pm 0.50$ & NS \\
FMD \% & $11.64 \pm 4.12$ & $17.56 \pm 4.49$ & $<0.01^{*}$ \\
NTG \% & $15.70 \pm 4.80$ & $18.48 \pm 6.38$ & $<0.03^{*}$ \\
\hline
\end{tabular}

*, statistical significance
Table 3 Inflammatory markers in both groups

\begin{tabular}{lccc}
\hline & $\begin{array}{c}\text { Subclinical } \\
\text { Hypothyroidism } \\
(\mathrm{n}=37)\end{array}$ & $\begin{array}{c}\text { Controls } \\
(\mathrm{n}=23)\end{array}$ & $P$ value \\
\hline IL-6 $(\mathrm{pg} / \mathrm{mL})$ & $2.207 \pm 1.510$ & $1.556 \pm 0.874$ & $<0.05^{*}$ \\
TNF-alpha $(\mathrm{pg} / \mathrm{mL})$ & $5.357 \pm 1.311$ & $2.765 \pm 0.784$ & $<0.01^{*}$ \\
hs-CRP $(\mathrm{mg} / \mathrm{L})$ & $0.624 \pm 0.157$ & $0.234 \pm 0.167$ & $<0.01^{*}$ \\
\hline
\end{tabular}

*, statistical significance

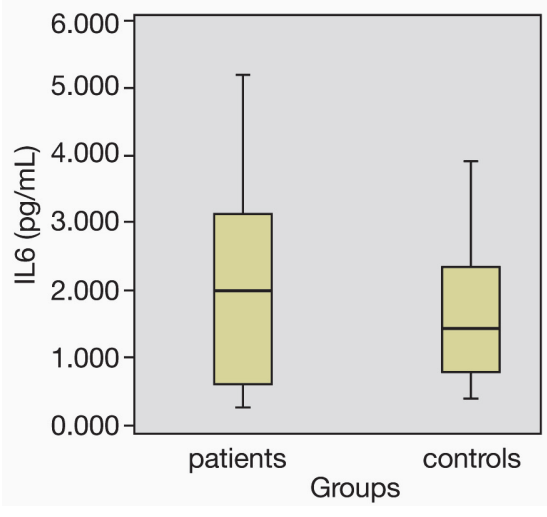

Fig. 1 IL-6 levels in groups

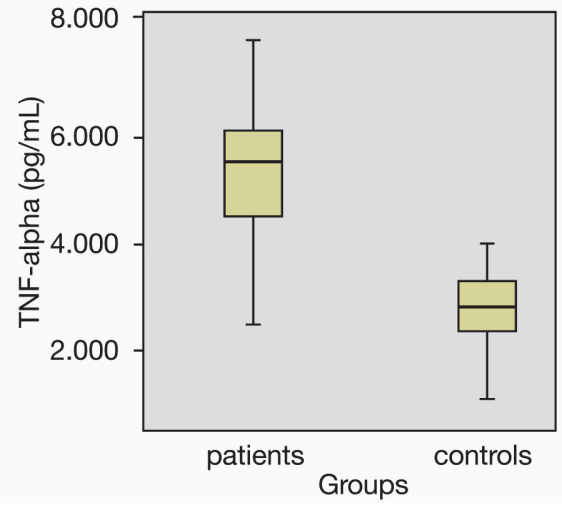

Fig. 2 TNF-alpha levels in groups

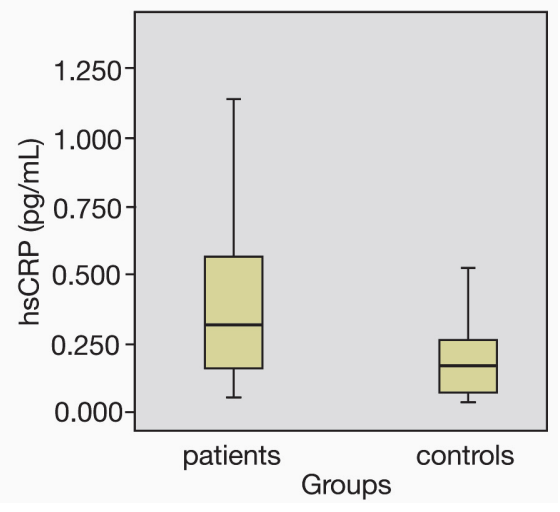

Fig. 3 Hs-CRP levels in groups 
resistant and there was not any difference either in fasting insulin or in glucose levels.

\section{Discussion}

Endothelium-dependent vascular response (FMD) was lower in the patient group. These findings support the hypothesis that there is endothelial dysfunction in subclinical hypothyroidism. Interestingly, inflammation markers were higher in the patient group. This situation might be one of the possible explanations for the pathogenesis of endothelial dysfunction in subclinical hypothyroidism.

In our study we also found that endothelium-independent vascular response (NTG) was reduced. However, none of the biochemical or inflammatory parameters were related to NTG.

Several factors could be contributed to endothelial dysfunction in SH. The best known of these factors is hyperlipidemia. It is a very well known fact that hyperlipidemia causes endothelial dysfunction per se by diminishing expression of endothelial nitric oxide synthase(eNOS) and by increasing asymmetric dimethylarginine levels, an eNOS endogenous inhibitor $[4,5]$. In SH there is an increase in LDL-cholesterol levels [6]. We also found an elevation in total, LDLcholesterol and triglyceride levels in SH group. This lipid profile could be at least a partial cause of the endothelial dysfunction in SH. Taddei et al. showed that levothyroxine administration and the consequent euthyroidism restoration and lipid profile normalisation reversed the impaired endothelium-dependent vasodilation only partially [7]. However, they did not find any reduction in endothelium-independent vasodilation, unlike our study.

Another factor that we have measured and could cause endothelial dysfunction in SH is inflammation. Acute and chronic inflammation is strongly related to endothelial dysfunction [8-10]. In our study, we planned to measure chronic inflammation markers and investigate possible relations between inflammatory markers and other parameters in patients with SH due to autoimmune thyroiditis. In order to do that, we ruled out $\mathrm{SH}$ cases due to other causes such as thyroidectomy, radioiodine ablation. We found higher levels of IL-6, TNF-alpha and hs-CRP in SH group. All of these inflammatory markers were correlated with FMD. These findings show that there is low grade chronic inflammation in patients with $\mathrm{SH}$ due to autoimmune
Table 4 Relations of FMD with other parameters

\begin{tabular}{lcc}
\hline Parameter & $\mathrm{R}$ & $P$ \\
\hline Age $($ year$)$ & -0.132 & 0.316 \\
BMI $\left(\mathrm{kg} / \mathrm{m}^{2}\right)$ & -0.109 & 0.409 \\
Waist circumference $(\mathrm{cm})$ & 0.056 & 0.673 \\
TSH $(\mu \mathrm{IU} / \mathrm{mL})$ & -0.195 & $0.002^{*}$ \\
Fasting plasma glucose $(\mathrm{mg} / \mathrm{dL})$ & -0.64 & 0.626 \\
Fasting insulin $(\mu \mathrm{IU} / \mathrm{mL})$ & -0.100 & 0.446 \\
HOMA-IR & -0.111 & 0.398 \\
Total cholesterol $(\mathrm{mg} / \mathrm{dL})$ & -0.494 & $<0.001^{*}$ \\
LDLcholesterol $(\mathrm{mg} / \mathrm{dL})$ & -0.475 & $<0.001^{*}$ \\
HDL-cholesterol $(\mathrm{mg} / \mathrm{dL})$ & -0.115 & 0.382 \\
Triglyceride $(\mathrm{mg} / \mathrm{dL})$ & -0.368 & $0.004^{*}$ \\
TNF-alpha $(\mathrm{pg} / \mathrm{mL})$ & -0.392 & $0.002^{*}$ \\
IL-6 $(\mathrm{pg} / \mathrm{mL})$ & -0.232 & $0.014^{*}$ \\
hs-CRP $(\mathrm{mg} / \mathrm{L})$ & -0.187 & $0.02^{*}$ \\
\hline
\end{tabular}

thyroiditis and we think that this inflammation may be one of the contributing factors that lead to endothelial dysfunction in patients with $\mathrm{SH}$.

IL-6 is an early and central modulator of inflammation and also has an important role in the course of the atherogenesis. It promotes endothelial dysfunction, smooth muscle cell proliferation and migration. It also recruits and activates inflammatory cells. Thus, IL-6 plays a central role in vascular inflammation [11]. In a recent report, increased concentrations of IL-6 and another pro-inlammatory cytokine IL- 15 were detected, possibly due to increased proliferation and increased synthesis of pro-inflammatory cytokines in T helper 17 cells in patients with autoimmune thyroiditis [12]. In addition, IL-6 level might be correlated with severity of hypothyroidism, because serum IL-6 level was found to be positively correlated with dose of levothyroxine replacement in hypothroidism due to autoimmune thyroiditis [13]. In our study patients did not clinically have hypothyroidism. They have had subcinical conditions however we detected higher levels of serum IL-6 and we also found a positive correlation between IL- 6 and FMD.

Another cytokine TNF-alpha is produced by macrophages, monocytes, epithelial cells and lymphocytes, and induces the production of interferon-gamma [14, 15]. The mRNA levels of TNF-alpha are significantly higher in thyroid tissues obtained from patients with autoimmune thyroiditis than in tissue obtained from the control group [16]. TNF-alpha is a major mediator of apoptosis as well as inflammation. The binding of TNFalpha to TNF- alpha receptors triggers a series of intracellular events that ultimately result in production of 
inflammatory cytokines via NF- $\mathrm{kB}$ activation or apoptosis $[17,18]$. In a recent study, reducing TNF-alpha with anti TNF-alpha antibodies had contributed to resolution of inflammation and inhibited fibrosis in granulomatous experimental autoimmune thyroiditis [19].

CRP is a marker of systemic inflammation and is used as a biomarker to assess cardiovascular risk in healthy subjects as well as in people with various disorders. It stimulates the release of inflammatory cytokines in monocytes. Elevated hs-CRP levels have been reported in SH [20]. In another study, authors demonstrated that patients with SH had higher levels of CRP and triglyceride compared to the levels in euthyroid persons [21]. The authors concluded that SH was associated with a low grade chronic inflammation and $\mathrm{SH}$ might be a contributing risk factor for development of cardiovascular disease in younger males. These findings are consistent with ours. We also found elevated hs-CRP levels in SH group in this study.

In conclusion, our findings suggest that there is endothelial dysfunction and low grade chronic inflammation in SH due to autoimmune thyroiditis. There are several contributing factors which can cause endothelial dysfunction in $\mathrm{SH}$ such as changes in lipid profile, hyperhomocysteinemia. According to our results low grade chronic inflammation may be one of these factors.

\section{References}

1. Quyyumi A (1998) Endothelial function in health and disease: new insights into the genesis of cardiovascular disease. Am J Med 105: 32S-39S.

2. Ross, R (1999) Atherosclerosis - an inflammatory disease. N Engl J Med 340: 115-126.

3. Coretti MC, Anderson TJ, Benjamin EJ, Celermajer D, Charbonneau F, Creager MA, Deanfield J, Drexler H, Gerhard- Herman M, Herrington D, Vallance P, Vita J \& Vogel R (2002) Guidelines for the ultrasound assessment of endothelium-dependent flowmediated vasodilation of the brachial artery. A Report of the International Brachial Artery Reactivity Task Force. J Am Coll Cardiol 39: 257-265.

4. Laufs U, La Fata V, Plutzky J, Liao JK (1998) Upregulation of endothelial nitric oxide synthase by HMG CoA reductase inhibitors.Circulation 97: 11291135.

5. Ito A, Tsao PS, Adimoolam S, Kimoto M, Ogawa T, Cooke JP (1999) Novel mechanism for endothelial dysfunction: dysregulation of dimethylarginine dimethylaminohydrolase. Circulation 99:3092-3095.

6. Efstathiadou Z, Bitsis S, Milionis HJ, Kukuvitis A, Bairaktari ET, Elisaf MS, Tsatsoulis A (2001) A lipid profile in subclinical hypothyroidism: is L-thyroxine substitution beneficial? Eur J Endocrinol 145: 705710 .

7. Taddei S, Caraccio N, Virdis A, Dardano A, Versari D, Ghiadoni L, Salvetti A, Ferrannini E, Monzani F 2003 Impaired endothelium-dependent vasodilatation in subclinical hypothyroidism: beneficial effect of levothyroxine therapy. J Clin Endocrinol Metab 88: 3731-3737 .

8. Hingorani AD, Cross J, Kharbanda RK, Mullen MJ, Bhagat K, Taylor M, Donald AE, Palacios M, Griffin GE, Deanfield JE, MacAllister RJ, Vallance P (2000) Acute systemic inflammation impairs endothelium-dependent dilatation in humans. Circulation 102: 994-
999.

9. Fichtlscherer S, Rosenberger G, Walter DH, Breuer S, Dimmeler S, Zeiher AM (2000) Elevated C-reactive protein levels and impaired endothelial vasoreactivity in patients with coronary artery disease. Circulation 102: 1000-1006 .

10. Kharbanda RK, Walton B, Allen M, Klein N, Hingorani AD, MacAllister RJ, Vallance P (2002) Prevention of inflammation-induced endothelial dysfunction: a novel vasculo-protective action of aspirin. Circulation 105: 2600-2604.

11. SchuettH,Luchtefeld M, Grothusen C, Grote K, Schieffer B (2009 ) How much is too much? Interleukin-6 and its signalling in atherosclerosis. Thromb Haemost 102: 215-222.

12. Figueroa-Vega N, Alfonso-Pérez M, Benedicto I, Sánchez-Madrid F, González-Amaro R, Marazuela M (2010) Increased circulating pro-inflammatory cytokines and Th17 lymphocytes in Hashimoto's thyroiditis. J Clin Endocrinol Metab 95: 953-962.

13. Papanas N, Papazoglou D, Papatheodorou K, Antonoglou C, Kotsiou S, Maltezos E (2006) Thyroxine replacement dose in patients with Hashimoto disease:a potential role for interleukin-6. Cytokine 35: 166-70.

14. Matsuno H, Yudoh K, Katayama R, Nakazawa F, Uzuki M, Sawai T, Yonezawa T, Saeki Y, Panayi GS, Pitzalis C, Kimura T et al. (2002) The role of TNF-alpha in the pathogenesis of inflammation and joint destruction in rheumatoid arthritis (RA): a study using a human RA/ SCID mouse chimera. Rheumatology (Oxford) 41: 329337.

15. Scheurich P, Thoma B, Ucer U, Pfizenmaier K (1987) Immunoregulatory activity of recombinant human tumor necrosis factor (TNF)-alpha: induction of TNF receptors on human $\mathrm{T}$ cells and TNF-alpha-mediated enhancement of T cell responses. J Immunol 138: 1786- 
1790.

16. Aust G, Heuer M, Laue S, Lehmann I, Hofmann A, Heldin NE, Scherbaum WA (1996) Expression of tumour necrosis factor-alpha (TNF-alpha) mRNA and protein in pathological thyroid tissue and carcinoma cell lines. Clin Exp Immunol 105: 148-154.

17. Aggarwal BB (2003) Signalling pathways of the TNF superfamily: a double-edged sword. Nat Rev Immunol 3: 745-756.

18. Muppidi, J. R., Tschopp, J., Siegel, R. M. (2004) Life and death decisions: secondary complexes and lipid rafts in TNF receptor family signal transduction. Immunity 21: 461-465.

19. Chen K, Wei Y, Sharp GC, Braley-Mullen H Decreasing
(2007) TNF-alpha results in less fibrosis and earlier resolution of granulomatous experimental autoimmune thyroiditis. J Leukoc Biol 81: 306-314.

20. Christ-Crain M, Meier C, Guglielmetti M Huber PR, Riesen W, Staub JJ, Müller B (2003) Elevated C-reactive protein and homocysteine values: cardiovascular risk factors in hypothyroidism? A cross-sectional and a double-blind, placebo-controlled trial. Atherosclerosis 166: 379-386.

21. Kvetny J, Heldgaard PE, Bladbjerg EM, Gram J (2004) Subclinical hypothyroidism is associated with a lowgrade inflammation, increased triglyceride and predicts cardiovascular disease in males below 50 years. Clin Endocrinol 61: 232-238. 